\title{
Continuous Manufacturing of Homogeneous Ultralow-Dose Granules by Twin-Screw Wet Granulation
}

\author{
Balázs Démuth', Gergő Fülöp ${ }^{1,2}$, Márk Kovács¹, Lajos Madarász', Máté Ficzere', Ákos Köte², \\ Bence Szabó1, Brigitta Nagy¹, Attila Balogh1', Kristóf Csorba³, Gábor Kaszás², Tibor Nagy², \\ Attila Bódis², György Marosi ${ }^{1 *}$, Zsombor Kristóf Nagy ${ }^{1}$
}

\footnotetext{
1 Department of Organic Chemistry and Technology, Faculty of Chemical Technology and Biotechnology, Budapest University of Technology and Economics, H-1111 Budapest, Müegyetem rakpart 3., Hungary

2 Formulation R\&D, Gedeon Richter Plc., H-1103 Budapest, Gyömrői utca 19-21., Hungary

${ }^{3}$ Department of Automation and Applied Informatics, Faculty of Electrical Engineering and Informatics, Budapest University of Technology and Economics, H-1117 Budapest, Magyar Tudósok körútja 2., Hungary

*Corresponding author, e-mail: gmarosi@mail.bme.hu
}

Received: 13 November 2019, Accepted: 13 January 2020, Published online: 23 March 2020

\begin{abstract}
Homogeneous ultralow-dose $(30 \mathrm{mg}$ ) tablets were prepared from perfectly free-flowing granules manufactured by continuous Twin-Screw Wet Granulation. The gravimetrically fed mixture of lactose and potato starch of low particle size was successfully agglomerated and the size enlargement technology proved to be very robust. Since the incorporated drug was dissolved in ethanolbased granulation liquid, the resulting homogeneity largely depended on the dosing of the applied liquid administering units. A peristaltic pump generated higher deviation of the drug content in tablets (Relative Standard Deviation (RSD): 7.7 \%) compared to a syringe pump (RSD: $2.3 \%$ ) or a piston pump (RSD: $4.6 \%$ ). This is due to the pulsation of the liquid flow generated by the peristaltic pump according to the real-time measured mass of the fed liquid. A good correlation was found between the RSD of the liquid mass flow (calculated from the recorded masses) and the RSD of the drug content. Based on the results, the goodness of Content Uniformity, as the most relevant critical quality attribute of low-dose products, was determined by the characteristics of the applied dosing units. The feeding characteristic of the different pumps could be easily measured by the introduced balance-based method and therefore, the applicability of the pumps could be evaluated.
\end{abstract}

\section{Keywords}

Twin-Screw Granulation, low-dose formulation, Content Uniformity, pump characteristics

\section{Introduction}

Granulation is one of the most commonly used technology in the pharmaceutical industry [1]. Its significance stems from the ability to produce enlarged particle sizes (granules) possessing superior downstream properties [2]. These include improved flowability, bulk density and compaction characteristics coupled with increased resistance to segregation ensuring reproducible tableting with exceptional quality [3].

Compared to the two conventional wet granulation methods (fluid bed and high-shear granulation), TwinScrew Wet Granulation (TSWG) definitely needs to be considered unique $[4,5]$. TSWG can be operated continuously granting numerous advantages over other traditional batch methods [6] such as easier scale-up, more uniform product quality, better controllability, etc. Since continuous technologies are heavily promoted by the authorities $[7,8]$, intense R\&D efforts are going into their possible industrial applications $[9,10]$. Numerous papers have been published based on the research conducted on TwinScrew Granulators [11-17].

The influence of some processing parameters (such as liquid-to-solid ratio, screw speed, input rate, screw configuration, barrel fill level, etc.) in course of TSWG has been thoroughly investigated from the start of the ascension of this technology [18-23]. The overall success evaluations of these studies are generally based on the reported granule properties (Particle Size Distribution (PSD), compressibility, friability, etc.) and consequent tablet 
characteristics (hardness, friability, time of disintegration, etc.). Interestingly, the evaluation of liquid distribution in the granulator is usually excluded from these investigations despite it undoubtedly has a significant impact on the resulting granule properties, especially on the PSD. According to El Hagrasy et al. [24], granules obtained by TSWG usually have bimodal size distribution due to the poor liquid distribution. This phenomenon was also observed by Dhenge et al. [25], although by applying a binder with a sufficiently high viscosity, the coveted mono-modal PSD was achieved. Yu et al. [26] showed that increasing hydrophobicity led to a more heterogeneous liquid distribution resulting in a relatively large portion of fines. Liquid distribution can also be examined by adopting a tracer method as demonstrated by a few papers in the literature [27-31]. Consequently, the understanding of the liquid distribution phenomenon during TSWG is crucial, and real-time monitoring techniques such as near-infrared chemical imaging can become a valuable tool in the future [32]. In special cases, such as when the API and the binder are co-dissolved in the granulating liquid, the requirement of a homogeneous liquid distribution can be even more pronounced.

Generally, a TSWG setup consists of two intermeshing, co-rotating screws placed in a barrel. The screws are made up of Conveying Elements, comb mixer elements and kneading blocks. These generate different levels of shear force on the materials enabling proper mixing and granulation of the powder mixture [33]. However, in order to achieve the desired granule properties, the performance of the feeding system needs to be consistent [24, 34]. Taking a regular Twin-Screw Granulation into consideration, at least one powder feeder and a liquid dosing unit are necessary to proceed with operations. Powder feeding can be challenging when the API is applied in micronized form possessing poor flow characteristics or charge electrostatically [35]. In terms of liquid or drug solution dosing, the regularly adopted peristaltic pumps may show pulsating flow profiles leading to undesirable granule properties [36, 37] or even API homogeneity issues if it is dissolved in the liquid. To produce low-dose tablets containing granules prepared by TSWG liquid dosing might be one of the most Critical Process Parameters.

In the case of low-dose (API content is below $2 \%$ [38]) drug products, pharmaceutical companies mostly choose wet granulation in order to meet the strict Content Uniformity requirements set by the authorities [39]. However, these are dominantly batch technologies that do not possess the advantages and conveniences of the aforementioned continuous ones. Only one publication mentions that a tracer molecule (riboflavin sodium phosphate dissolved in liquid) could be homogeneously distributed in granules after TSWG, however, the homogeneity studies were not extended to tablets [19]. Consequently, the main objective of this work was to produce novel homogeneous ultralow-dose tablet batches based on a continuous TSWG technology. In order to achieve this challenging task, the following subgoals were set:

- develop a technology consisting of TSWG, fluid-bed drying, sieving, and tableting generating ultralowdose tablets with adequate Content Uniformity being the most important Critical Quality Attribute (CQA);

- examine the impact of different pumps as Critical Process Parameters (CPP) on API homogeneity and characterize them in terms of variability of the liquid addition rate by real-time mass measurements;

- compare the outcome of the obtained Content Uniformities to the results of the balance-based pump characterization in order to evaluate the applicability of certain dosing units from a CQA standpoint.

During the experimental work, a poorly flowable mixture (ideal for granulation) of $\alpha$-lactose monohydrate and potato starch was granulated with polyvinylpyrrolidone K30. For the non-placebo experiments, carvedilol (CAR), a non-selective $\beta$-blocking agent, was chosen as model API (the drug was selected for analytical reasons, not for any biological relevance at such a low concentration). According to the authors' best knowledge, this is the first time when tablets consisting of an API with an extremely low dose $(30 \mu \mathrm{g})$ was developed through a continuous TSWG technology. Ethanol was selected as the granulating liquid since it dissolves the API easily as opposed to water. Pumps with different working principles (peristaltic, piston and syringe pump) have been compared in terms of ability to generate granules with homogeneous API content. By applying carvedilol in the liquid phase, the resulting homogeneity will mainly depend on the adopted dosing units and the necessity of blend uniformity justification in the lactose-starch-API mixture could be avoided.

\section{Materials and methods}

\subsection{Materials}

Carvedilol (CAR) with a purity of $\geq 98 \%$ and a melting point of $117{ }^{\circ} \mathrm{C}$ along with $96 \%$ ethanol and methanol were provided by Sigma-Aldrich (Budapest, Hungary). 
Fine $\alpha$-lactose monohydrate (GranuLac ${ }^{\circledR} 230$ mesh) was supplied by Meggle Pharma (Wasserburg, Germany), Kollidon ${ }^{\circledR} 30$ (Povidone, PVPK30) was shipped by BASF (Ludwigshafen, Germany) and potato starch was provided by Roquette Pharma (Lestrem, France). For tableting, Aerosil® 200 (fumed silica) was supplied by Evonik Industries (Essen, Germany), while stearic acid and magnesium-stearate were given by Hungaropharma Ltd. (Budapest, Hungary).

\subsection{Granule production}

Granulation experiments were conducted in a multifunctional continuous twin-screw equipment (TS16, Quick 2000 Ltd, Hungary) operated in wet granulation mode with a basic screw speed of $150 \mathrm{rpm}$ (revolutions per minute), a screw diameter of $16 \mathrm{~mm}$ ( $25 \mathrm{~L} / \mathrm{D}$ ratio), and a set configuration shown in Fig. 1 (CE: Conveying Elements, KZ: Kneading Zones). The Kneading Zones consisted of individual elements set up in a $45^{\circ}$ angle with a forward configuration (first zone 5 elements; second zone: 15 elements; third zone: 10 elements). Elements before the Kneading Zones were Conveying Elements with small pitch size to accumulate enough materials for the granulation. Elements after the Kneading Zones were Conveying Elements with large pitch size to facilitate the transport of the granules. The TSG was operated at room temperature, without applying any additional heating.

A gravimetric feeder (type: DDW-MD0-MT HYD ISC plus, Brabender Technologie, Duisburg, Germany) was adopted in order to dispense the solid blend of lactose and starch into the Twin-Screw Granulator (TSG) with applying a constant feeding rate of $1 \mathrm{~kg} / \mathrm{h}$. These pre-blends were carried out manually in plastic bags within a duration of 5 minutes. The granulation liquid (PVPK30 and CAR were dissolved in ethanol) was dosed into the second zone of the device using a peristaltic pump (Watson-Marlow 120U, Wilmington, MA, USA) or a syringe pump (SEP10S Plus, Aitecs, Vilnius, Lithuania) or a piston pump (JASCO PU-980, Hachioji, Japan) with a constant feed rate of $165 \mathrm{ml} / \mathrm{h}$ (in case of the peristaltic pump, the feeding speed was set based on a previously made calibration).

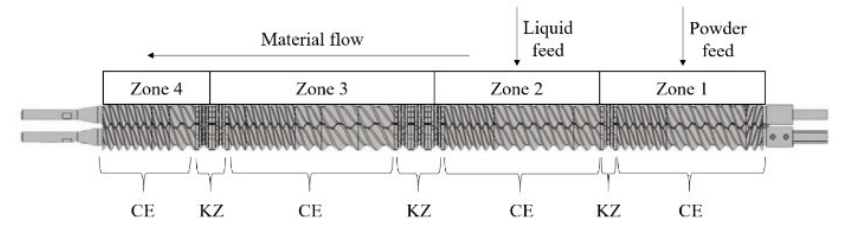

Fig. 1 The adopted screw configuration of the Twin-Screw Granulator
In each case, the liquid was fed through a silicone tube with an inner diameter of $3.1 \mathrm{~mm}$. The peristaltic pump was applied for the placebo experiments.

The prepared wet granules were then subsequently dried in a lab-scale fluid bed dryer (Aeromatic Strea-1, Düsseldorf, Germany) with a drying temperature of $50{ }^{\circ} \mathrm{C}$ in 5 minutes, and lastly passed through a $0.8 \mathrm{~mm}$ hand sieve.

\subsection{Granule characterization}

The residual moisture contents of the dried granules were determined by a moisture analyzer (Sartorius MA 40, Göttingen, Germany). In each case, granules with an approximate weight of 2 grams were evaluated $\left(105^{\circ} \mathrm{C}, 3 \mathrm{~min}\right)$.

The Particle Size Distribution (PSD) measurements were measured by a Malvern Mastersizer 2000 laser diffraction device (Malvern Pananalytical, Malvern, UK) in solid state. The dispersive air pressure was set to 1 bar.

Bulk and tapped density measurements were carried out according to the USP [40] by adopting an SVM 12 tapped density tester (ERWEKA GmbH, Heusenstamm, Germany). A total granule weight of 100 grams was evaluated accordingly. For tapped density measurements, the number of taps was set to 1200 .

Granule flowability measurements were carried out with a funnel described in ASTM D 1895 and ISO R60 (orifice was $10 \mathrm{~mm}$ wide). The time necessary for 100 grams of granule to flow out of the funnel was measured by a stopwatch. The experiments were done in triplicates.

\subsection{Tableting and physical tablet tests}

Prior to compaction, the final powder mixture was prepared through simple homogenization steps. The granules were blended with the components of the outer phase in plastic bags according to the following chronological order: glidant (1 min), stearic acid (30 sec) and lastly magnesium stearate $(30 \mathrm{sec})$. The powder mixtures were compressed into tablets on a Piccola tablet rotary press (Riva, Aldershot, UK) equipped with concave punches of $6 \mathrm{~mm}$ diameter and no markings. Turret speed was 40 rpm, FillO-Matic was $15 \mathrm{rpm}$ and main compression force was between 4 and $10 \mathrm{kN}$.

Batch characteristics are detailed in Table 1. (Due to confidential reasons, the quantitative composition could not be disclosed.)

The compressed tablets were evaluated by standard tests such as tablet weight, thickness, hardness, friability measurements and time of disintegration. Most of these physical parameters were determined by an Erweka 
Table 1 Batch characteristics

\begin{tabular}{lcccc}
\hline $\begin{array}{l}\text { Applied } \\
\text { API }\end{array}$ & $\begin{array}{c}\text { API dose } \\
(\mu \mathrm{g})\end{array}$ & $\begin{array}{c}\text { Tablet weight } \\
(\mathrm{mg})\end{array}$ & $\begin{array}{c}\text { Batch size } \\
(\text { tablets })\end{array}$ & $\begin{array}{c}\text { Total weight } \\
(\mathrm{g})\end{array}$ \\
\hline Carvedilol & 30 & 85 & 6000 & 510 \\
\hline
\end{tabular}

MultiCheck apparatus, while friability tests were conducted in a Pharmatest PTFR-A analyzer and disintegration time was measured in a Pharmatest PTZ-Auto disintegration tester in water $\left(37 \pm 0.5^{\circ} \mathrm{C}\right)$. In total, 10 tablets were examined by the MultiCheck, 6 tablets were studied by the PTZ-Auto and tablets with the sum weight of 6.5 grams were evaluated by the PTFR-A. Friability tests were made according to the USP with 100 turns in 4 min [41].

\subsection{Content Uniformity (CU) analysis}

$\mathrm{CU}$ was determined by High-Performance Liquid Chromatography (HPLC). Ten randomly chosen tablets were individually placed into $10 \mathrm{~mL}$ volumetric flasks where they were disintegrated in a mixture of methanol and purified water (1:1) within an ultrasonic bath in $15 \mathrm{~min}$. Upon completion, the suspensions were filtered by a $0.45 \mu \mathrm{m}$ polytetrafluoroethylene (PTFE) syringe filter. The examinations were carried out on a reversed-phase HPLC column (Agilent 1200 series LC system, Santa Clara, CA, USA) with a gradient elution of $0.1 \mathrm{M}$ phosphoric acid and acetonitrile at $25{ }^{\circ} \mathrm{C}$ (flow rate was set to $1.0 \mathrm{ml} / \mathrm{min}$ ). The concentration of CAR was determined based on the UV absorption of the injected solution at $285 \mathrm{~nm}$.

\subsection{Measurement of the liquid addition rate of different pumps}

In these experiments, the granulating liquid (ethanolic solution of PVPK30) was fed from a bottle to a plastic glass by using the aforementioned pumps and tubes. The plastic glass was placed on a Sartorius MC-1 AC 210 P analytical balance (Göttingen, Germany) connected to a laptop. On the laptop, an in-house built software was run, which received the mass recorded on the balance in real-time (the data was automatically written into a text file). The mass of the liquid was recorded every 0.2 seconds. The mass flow was calculated based on the masses recorded 5 seconds separately.

\section{Results and discussion}

As it was shortly summarized in the introduction, our goal was to produce low-dose API-containing, highly homogeneous tablets compressed from continuously manufactured granules fabricated by a TSWG technology. However, before the actual experiments with CAR began, placebo batches were produced in order to evaluate the quality of the granules (and later tablets). The manufactured granules were examined thoroughly (PSD, granulometry, residual moisture content) followed by compression into tablets. Once these preliminary tests were concluded, the experiments with CAR could be performed.

\subsection{Placebo results}

\subsubsection{Granule production}

As it was mentioned in the introduction part, the effect of parameter changing during continuous TSWG is a highly examined subject in the literature. Therefore, it was not included in our goals to cover this topic. The parameter settings of the performed experiments are summarized in Table 2.

During the initial experiment, the PVP was dissolved in ethanol to form the granulating liquid to be dosed into the second zone of the continuous TSG equipment. In the next (downstream) step, the applicability of wet sieving was compared to the results of standard dry sieving. This experiment was deemed necessary in order to determine its effect on the consequent granule PSD. The final trial, when the PVP was pre-blended with lactose and starch to form a premix, is considered notable from the aspect of industrial adaptability of TSWG. By simply homogenizing the binder with the other excipients, the time needed to prepare the granulation liquid (pure solvent) was greatly reduced. Ultimately, this method decreases the complexity of the granulation. However, it is unknown if it will change the granulation mechanism and/or impair the PSD.

Upon completion, the wet granules were dried in a fluid bed dryer. During this operation, it is necessary to keep the product temperature at a reasonably low level to protect the future batches (that will incorporate API) from potential degradation.

Table 2 TSWG settings of the placebo granulations

\begin{tabular}{lccccc}
\hline Settings & $\begin{array}{c}\text { PVP } \\
\text { quantity } \\
(\%)\end{array}$ & $\begin{array}{c}\text { Screw } \\
\text { speed } \\
(\mathrm{rpm})\end{array}$ & $\begin{array}{c}\text { Binder } \\
\text { addition }\end{array}$ & $\begin{array}{c}\text { Drying } \\
\left({ }^{\circ} \mathrm{C}, \mathrm{min}\right)\end{array}$ & $\begin{array}{c}\text { Sieving } \\
\text { (before or } \\
\text { after drying })\end{array}$ \\
\hline $\begin{array}{l}\text { Dissolved } \\
\text { PVP }\end{array}$ & 3 & 150 & Solution & $50 ; 5$ & After \\
$\begin{array}{l}\text { PVP } \\
\text { premix }\end{array}$ & 3 & 150 & Premix & $50 ; 5$ & After \\
$\begin{array}{l}\text { Wet } \\
\text { sieving }\end{array}$ & 3 & 150 & Solution & $50 ; 5$ & Before \\
\hline
\end{tabular}




\subsubsection{Granule characterization}

The continuously manufactured placebo granules were examined and evaluated by PSD, flowability, residual moisture content and lastly bulk and tapped density measurements. The results along with the correspondent data of the starting lactose-starch mixture are detailed in Table 3.

Based on the density values, the compressibility indices and Hausner ratios were also determined. These non-intrinsic powder properties are easily calculated and provide valuable information regarding flow characteristics [42]. According to the results, each experiment produced highly flowable granules, confirmed not only by the calculated values but by the highly successful funnel flowability tests (10-12 s/100 g). In comparison, the starting lactose-starch powder mixture could not pass through the orifice. Interestingly, the product made by wet sieving exhibited good flow properties in spite of the significantly lower particle size (and less advantageous PSD, see Fig. 2).

The moisture content results demonstrate that none of the manufactured batches contained more than $4 \%$ of moisture. The received values enabled the consequent tableting process to be carried out easily. No signs of capping, lamination (a possible cause of low moisture content) and sticking (a possible cause of high moisture content) were observed throughout the operation. Wet sieving, since smaller particles were dried, facilitated the evaporation of ethanol, thus by applying the same drying method, lower residual moisture content was achieved (3.19\%).

Out of all granule characterization methods, PSD measurements and their evaluations can be considered as the most vital and important [43], since it provides direct feedback on the actual success or failure of the size enlargement process. Prior to granulation, the desired range was determined to be between 90 and $1000 \mu \mathrm{m}$ following sieving with a unimodal distribution. At this range, granules generally possess the necessary attributes needed for the upcoming manufacturing stages [44]. The results of the PSD measurements are shown in Fig. 2.

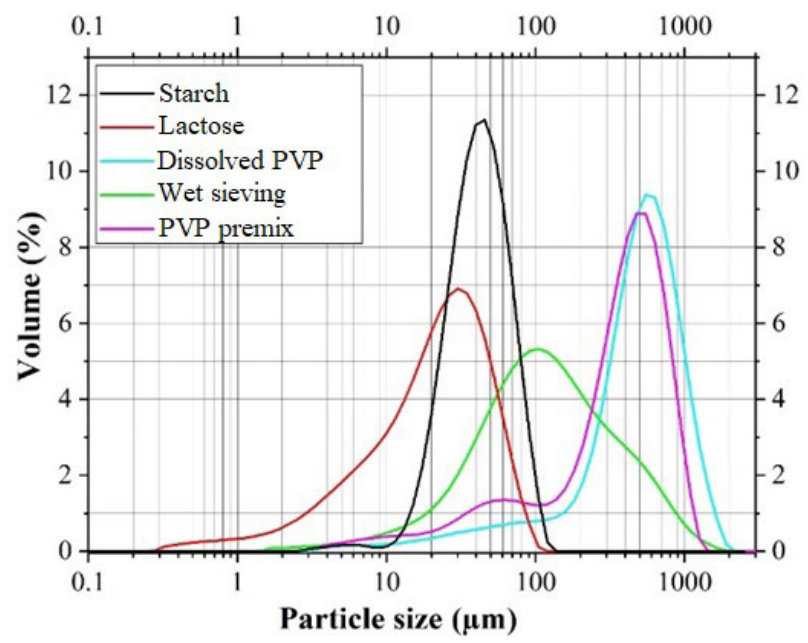

Fig. 2 Particle Size Distribution results based on laser diffraction measurements following sieving $(0.8 \mathrm{~mm})$

Based on the PSD results of the starting materials (lactose, starch), their small average particle size is clearly apparent. The $d(0.9)$ values of lactose and starch were found to be 57 and 79 microns making their possible future application without granulation impossible. Contrarily, the PSDs of the granulated samples were more favorable as the products had $d(0.9)$ values in the upper hundred-micron range. These results demonstrate the applicability of this continuous TSWG technology for size enlargement purposes. Granulation carried out with the initial dissolved PVP settings produced high-quality granules with a unimodal distribution profile [24]. The premixing of PVP caused a slight increase of fines indicating that the binder was unable to blend perfectly with the excipients resulting in an incomplete granulation, although the final result was still deemed acceptable (majority of the granules belonged to the desired 90-1000 $\mu \mathrm{m}$ range and the $d(0.9)$ value remained above $800 \mu \mathrm{m})$. The implementation of wet sieving produced great amounts of fines suggesting that the bonds constructed by the binder between the excipient particles can be broken before the subsequent drying step could solidify them. Based on

Table 3 The measured characteristics of the starting powder mixture and the granules

\begin{tabular}{|c|c|c|c|c|c|c|c|}
\hline Characteristics & $\begin{array}{l}\text { Bulk density } \\
\qquad\left(\mathrm{g} / \mathrm{cm}^{3}\right)\end{array}$ & $\begin{array}{l}\text { Tapped density } \\
\left(\mathrm{g} / \mathrm{cm}^{3}\right)\end{array}$ & $\begin{array}{c}\text { Compressibility } \\
\text { index }(\%)\end{array}$ & Hausner ratio & $\begin{array}{l}\text { Flowability } \\
\text { (s/100 g) }\end{array}$ & $d(0.9)(\mu \mathrm{m})$ & $\begin{array}{c}\text { Residual } \\
\text { moisture (\%) }\end{array}$ \\
\hline $\begin{array}{l}\text { Lactose-starch } \\
\text { premix }\end{array}$ & 0.488 & 0.677 & 27.92 & 1.39 & Non-flowing & $\begin{array}{l}\text { Lactose: } 57 \\
\text { Starch: } 79\end{array}$ & 3.34 \\
\hline Dissolved PVP & 0.576 & 0.640 & 10.00 & 1.11 & $10.75 \pm 0.06$ & 1084 & 3.98 \\
\hline PVP premix & 0.550 & 0.625 & 12.00 & 1.14 & $11.01 \pm 0.52$ & 831 & 3.61 \\
\hline Wet sieving & 0.499 & 0.559 & 10.73 & 1.12 & $12.05 \pm 0.21$ & 506 & 3.19 \\
\hline
\end{tabular}


this outcome, the potential application of wet sieving in the upcoming API experiments was discarded. The granulation with the placebo system was deemed successful, and the obtained granules were appropriate. Therefore, no further optimization of TSWG seemed necessary.

\subsubsection{Tableting}

Two of the discussed three kinds of granules were chosen to be compressed into tablets for further investigation. The batches manufactured with the dissolved PVP and the PVP premix were selected and processed accordingly. These two samples were chosen since the mechanism of the granulation (the binding bridge formation among the particles) might be different, which can have a significant impact on the resulting tablet properties. Upon completion of the final powder mixtures, the blends were compressed into tablets and their characteristics were measured and evaluated.

The results are detailed in Table 4. According to the results, the batches containing PVP in premix produced slightly stronger tablets with the same compression force, while the average time of disintegration was approximately identical. In each case, the disintegration limit of 30 minutes set by the Pharmacopeia [45] was easily achieved (2-3 minutes). Average tablet hardness values were ranging from 75 to $143 \mathrm{~N}$, monotonically increasing with compression force but reaching a close to the maximum value already at $8 \mathrm{kN}$ (dissolved PVP) and $6 \mathrm{kN}$ (PVP premix). Tablets produced with the dissolved binder had significantly lower friability at all compression forces, which can be attributed to the enhanced binding ability of PVP in a solution, but the possibility of reaching the maximum limit of $1 \%$ was never at risk. Based on the obtained results of the placebo system, the granulation method with dissolved PVP in the granulation liquid was chosen for the experiments with the active ingredient.

\subsection{The results of CAR tablets}

\subsubsection{Content Uniformity of CAR tablets}

As it was briefly mentioned in the introduction, meeting the Content Uniformity criteria in low-dose drug products can be very challenging [46]. High standard deviation of the incorporated drug can particularly be characteristic of low-dose formulations. Studies conducted on this field based on continuous TSWG are very limited. In order to obtain highly homogeneous tablet batches, CAR was dissolved in the granulating liquid, since the accurate dosing of the API with a continuous powder feeder at such a low concentration $(0.035 \mathrm{w} / \mathrm{w} \%)$ can make the homogenization even more challenging.

In accordance with the preliminary placebo tablet results, the initial dissolved PVP settings were chosen to produce the CAR-containing batches based on the TSWG technology. Since the API content is extremely low, its potentially unfavorable effect on the success of granulation was deemed negligible. Finding the most Critical Process Parameter affecting homogeneity can be a cornerstone of this technology. As CAR was dissolved in the ethanol, it seemed worthy to investigate the liquid dispensing unit, especially the applied pump. Throughout these experiments, three pumps with different working principles (peristaltic pump, syringe pump, piston pump) were adopted in order to reveal whether the type of the employed pump has any significant effect on the outcome of success in CAR homogeneity. Drug content of the final dosage forms was measured and their RSD was subsequently calculated. These are summarized in Fig. 3.

According to the results, the application of the peristaltic pump produced larger RSD values in the tablets indicating a highly inhomogeneous batch. The apparent pulsating flow observed throughout the operation of the peristaltic pump ultimately leads to inconsistent feeding, which prevents the low-dose API to evenly blend with the other

Table 4 Physical test results of the placebo tablets compressed from granules manufactured by TSWG

\begin{tabular}{|c|c|c|c|c|c|c|c|c|}
\hline Compression force $(\mathrm{kN})$ & 4 & 6 & 8 & 10 & 4 & 6 & 8 & 10 \\
\hline Granule production method & $\begin{array}{c}\text { Dissolved } \\
\text { PVP }\end{array}$ & $\begin{array}{l}\text { Dissolved } \\
\text { PVP }\end{array}$ & $\begin{array}{c}\text { Dissolved } \\
\text { PVP }\end{array}$ & $\begin{array}{c}\text { Dissolved } \\
\text { PVP }\end{array}$ & PVP premix & PVP premix & PVP premix & PVP premix \\
\hline Weight (mg) & $83.4 \pm 0.6$ & $83.9 \pm 0.7$ & $83.9 \pm 0.7$ & $83.4 \pm 0.8$ & $86.7 \pm 0.8$ & $88.4 \pm 0.4$ & $84.0 \pm 0.4$ & $83.8 \pm 0.5$ \\
\hline Thickness (mm) & $2.58 \pm 0.01$ & $2.53 \pm 0.01$ & $2.48 \pm 0.01$ & $2.45 \pm 0.02$ & $2.64 \pm 0.03$ & $2.61 \pm 0.01$ & $2.47 \pm 0.01$ & $2.45 \pm 0.02$ \\
\hline Diameter (mm) & $5.96 \pm 0.01$ & $5.96 \pm 0.01$ & $5.96 \pm 0.01$ & $5.98 \pm 0.02$ & $5.97 \pm 0.01$ & $5.97 \pm 0.01$ & $5.96 \pm 0.01$ & $5.99 \pm 0.02$ \\
\hline Hardness $(\mathrm{N})$ & $75 \pm 7$ & $101 \pm 13$ & $134 \pm 13$ & $136 \pm 10$ & $87 \pm 10$ & $127 \pm 12$ & $134 \pm 9$ & $143 \pm 5$ \\
\hline Friability (\%) & 0.248 & 0.282 & 0.26 & 0.292 & 0.360 & 0.352 & 0.324 & 0.415 \\
\hline Disintegration (s) & $115 \pm 43$ & $131 \pm 39$ & $164 \pm 32$ & $196 \pm 64$ & $126 \pm 32$ & $129 \pm 45$ & $168 \pm 30$ & $119 \pm 75$ \\
\hline
\end{tabular}




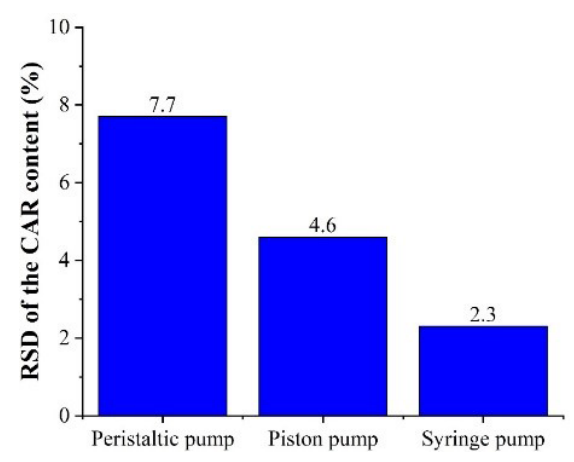

Fig. 3 Relative Standard Deviation of the CAR content in tablets (granules were made with different pumps)

materials. As opposed to the peristaltic pump, syringe and piston pump ensured lower RSDs of the CAR content. The best result was achieved by applying the syringe pump. It seems obvious that the type of pump has a significant effect on the homogeneity of the API. It can be claimed that when the API is dissolved in the granulating liquid, the successful result of the most important CQA (Content Uniformity) of low-dose products can be linked to the liquid dosing rate (and thus, the type of the pump) as the most important correspondent CPP. Defining CPPs and CQAs in pharmaceutical development are an integral part of the Quality by Design (QbD) guidelines promoted by the Food and Drug Administration [47].

\subsubsection{Pump characteristics - the dosing profiles}

As the liquid dosing rate was proved to be a critical parameter, it is worth to put effort into determining it with a simple method (that ultimately could be used as an in-line soft sensor too) as suggested by the $\mathrm{QbD}$ guidelines.

In order to compare the different pumps, the liquid addition rate of the three applied types was measured as indicated in Section 2.6. The recorded rate for one minute in case of each pump is shown in Fig. 4. The tested average feeding speeds were realistic, similar to one applied during normal granulation runs.

Not surprisingly, the least consistent feeding was provided by the peristaltic pump showing a sinusoidal profile (RSD of the mass flow: $10 \%$ ). With the piston pump, more consistent dosing of the ethanolic solution was achieved (RSD: $5.6 \%$ ). A very steady dispensing of the liquid was realizable with the syringe pump (RSD: $3.4 \%$ ). Therefore, the application of the latter two pumps is recommended when homogeneity of the liquid (and possibly, the dissolved drug) is of great importance. The inconsistent feeding of the granulating liquid may lead to more

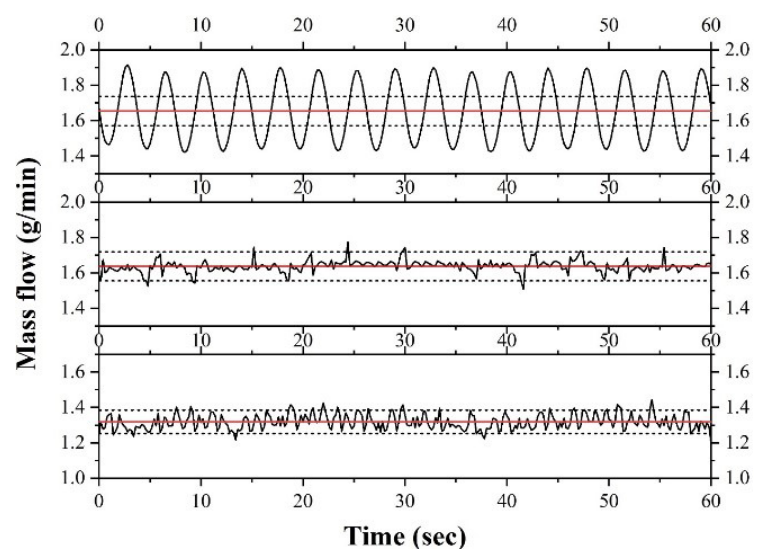

Fig. 4 Liquid dosing rates of (a) peristaltic pump (b) piston pump (c) syringe pump (red lines denotes the average mass flow values while the dashed lines mark the $\pm 5 \%$ deviation

disadvantageous PSDs [12] (besides the inhomogeneous drug distribution) especially if the granulating agent is dissolved in it.

If the RSD values of the mass flows belonging to the different pumps are compared to the RSD values of the drug content in tablets, a good correlation can be found (Fig. 5).

The linear correlation means that based on the measurement of the liquid flow rate (as CPP), the Content Uniformity (as CQA) can be estimated in this case. Looking into the applicability of this system is the continuation of this work.

Based on these profiles produced through simple tests, the adaptability of certain pumps in future granulation experiments could be determined. Additionally, only minimal amounts of material - even without an API - is necessary to carry out these investigations. By the upcoming development of a residence time distribution model (based on a former approach [48]), an even more precise method will be established to estimate Content Uniformity and

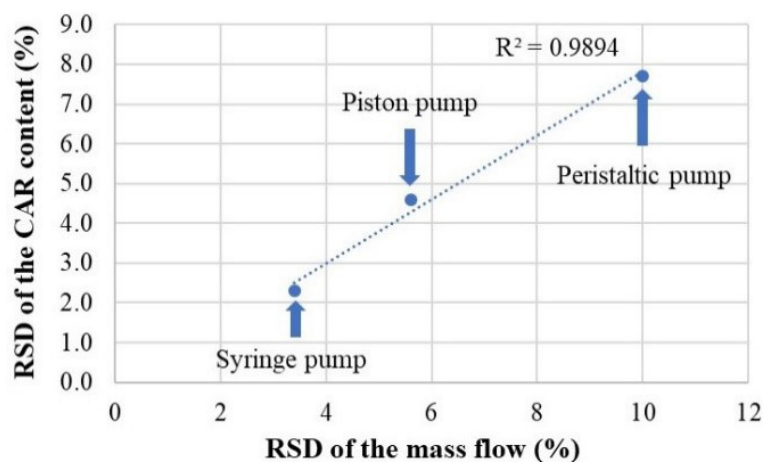

Fig. 5 Correlation between RSD values of mass flows and of CAR content 
to determine which profiles are acceptable and which are not for certain purposes. Ultimately, this will be the "digital twin" of the continuous TSWG unit.

\section{Conclusion}

Placebo tablet batch productions based on continuous Twin-Screw Wet Granulation proved to be a robust technology resulting in excellent physical properties. This developed system served as a foundation for the investigation on how to manufacture highly homogeneous low-dose tablets by a continuous granulating platform.

This work demonstrates the inaugural preparation of homogeneous ultralow-dose tablet batches based on a continuous Twin-Screw Wet Granulation technology. With the binder and the API dissolved in the granulating liquid, pump characteristic (i.e. the liquid dosing rate) was determined as the most important Critical Process Parameter (CPP) in terms of acceptable homogeneity and consequent Content Uniformity (CQA). The feeding characteristic of the different pumps could be determined easily by the introduced simple balance-based method and this novel approach can be applied for following the granulation process as an in-line process analytical solution. Pumps showing no pulsation of

\section{References}

[1] Ennis, B. J. "Theory of granulation: An engineering perspective", In: Parikh, D. M. (ed.) Handbook of Pharmaceutical Granulation Technology, Informa Healthcare, Hoboken, NJ, USA, 2005, pp. 7-78.

https://doi.org/10.1201/9780849354953-5

[2] Suresh, P., Sreedhar, I., Vaidhiswaran, R., Venugopal, A. "A comprehensive review on process and engineering aspects of pharmaceutical wet granulation", Chemical Engineering Journal, 328, pp. 785-815, 2017.

https://doi.org/10.1016/j.cej.2017.07.091

[3] van den Ban, S., Goodwin, D. J. "The Impact of Granule Density on Tabletting and Pharmaceutical Product Performance", Pharmaceutical Research, 34(5), pp. 1002-1011, 2017. https://oi.org/10.1007/s11095-017-2115-5

[4] Keleb, E. I., Vermeire, A., Vervaet, C., Remon, J. P. "Twin screw granulation as a simple and efficient tool for continuous wet granulation", International Journal of Pharmaceutics, 273(1-2), pp. 183-194, 2004.

https://doi.org/10.1016/j.ijpharm.2004.01.001

[5] Seem, T. C., Rowson, N. A., Ingram, A., Huang, Z., Yu, S., de Matas, M., Gabbot, I., Reynolds, G. K. "Twin screw granulationA literature review", Powder Technology, 276, pp. 89-102, 2015. https://doi.org/10.1016/j.powtec.2015.01.075

[6] Plumb, K. "Continuous Processing in the Pharmaceutical Industry: Changing the Mind Set", Chemical Engineering Research and Design, 83(6), pp. 730-738, 2005.

https://doi.org/10.1205/cherd.04359 the fed liquid (syringe pump, piston pump) can produce granules with more homogeneous drug distribution compared to regularly applied peristaltic pumps. The peristaltic pump was shown to feed the liquid sinusoidally, which causes an inhomogeneous distribution of the API. Consequently, in the case of low-dose drug development with continuous Twin-Screw Granulation based on dissolving the API(s) in the granulating liquid, the application of a pulse-free dosing pump is of great importance.

\section{Acknowledgements}

This work was financed by the National Research, Development, and Innovation Fund (NRDIOF) of Hungary in the frame of FIEK_16-1-2016-0007 (Higher Education and Industrial Cooperation Center) project. The authors are thankful for the János Bolyai Research Scholarship of the Hungarian Academy of Sciences. This work was also supported by OTKA grants K-112644, PD-128241, KH-124541 and GINOP-2.1.1-15-2015-00541 and GINOP2.1.7-15-2016-01301 of the NRDIOF of Hungary.

\section{Declaration of interest}

The authors report no conflict of interest.

[7] Woodcock, J. "Pharmaceutical Quality for the $21^{\text {st }}$ Century A Risk-Based Approach Progress Report", [pdf] U.S. Food \& Drug Administration, Center for Drug Evaluation and Research, Silver Spring, MD, USA, 2004. Available at: https://www.fda.gov/ media/77391/download [Accessed: 21 November 2018]

[8] Chatterjee, S. "FDA Perspective on Continuous Manufacturing", [pdf] U.S. Food \& Drug Administration, Center for Drug Evaluation and Research, Silver Spring, MD, USA, 2012. Available at: https://www.fda.gov/media/85366/download [Accessed: 30 November 2018]

[9] Beer, P., Wilson, D., Huang, Z., De Matas, M. "Transfer from High-Shear Batch to Continuous Twin Screw Wet Granulation: A Case Study in Understanding the Relationship Between Process Parameters and Product Quality Attributes", Journal of Pharmaceutical Sciences, 103(10), pp. 3075-3082, 2014. https://doi.org/10.1002/jps.24078

[10] Zomer, S., Zhang, J., Talwar, S., Chattoraj, S., Hewitt, C. "Multivariate monitoring for the industrialisation of a continuous wet granulation tableting process", International Journal of Pharmaceutics, 547(1-2), pp. 506-519, 2018. https://doi.org/10.1016/j.ijpharm.2018.06.034

[11] Liu, H., Galbraith, S. C., Ricart, B., Stanton, C., Smith-Goettler, B., Verdi, L., O'Connor, T., Lee, S., Yoon, S. "Optimization of critical quality attributes in continuous twin-screw wet granulation via design space validated with pilot scale experimental data", International Journal of Pharmaceutics, 525(1), pp. 249-263, 2017. https://doi.org/10.1016/j.ijpharm.2017.04.055 
[12] Madarász, L., Nagy, Z. K., Hoffer, I., Szabó, B., Csontos, I., Pataki, H., Démuth, B., Szabó, B., Csorba, K., Marosi, G. "Real-time feedback control of twin-screw wet granulation based on image analysis", International Journal of Pharmaceutics, 547(1-2), pp. 360-367, 2018.

https://doi.org/10.1016/j.ijpharm.2018.06.003

[13] Meier, R., Thommes, M., Rasenack, N., Krumme, M., Moll, K.-P., Kleinebudde, P. "Simplified formulations with high drug loads for continuous twin-screw granulation", International Journal of Pharmaceutics, 496(1), pp. 12-23, 2015.

https://doi.org/10.1016/j.ijpharm.2015.05.060

[14] Nagy, B., Farkas, A., Gyürkés, M., Komaromy-Hiller, Sz., Démuth, B., Szabó, B., Nusser, D., Borbás, E., Marosi, Gy., Nagy, Zs. K. "In-line Raman spectroscopic monitoring and feedback control of a continuous twin-screw pharmaceutical powder blending and tableting process", International Journal of Pharmaceutics, 530(1-2), pp. 21-29, 2017.

https://doi.org/10.1016/j.ijpharm.2017.07.041

[15] Silva, A. F., Vercruysse, J., Vervaet, C., Remon, J. P., Lopes, J. A., De Beer, T., Sarraguça, M. C. "Process monitoring and evaluation of a continuous pharmaceutical twin-screw granulation and drying process using multivariate data analysis", European Journal of Pharmaceutics and Biopharmaceutics, 128, pp. 36-47, 2018. https://doi.org/10.1016/j.ejpb.2018.04.011

[16] Kallakunta, V. R., Tiwari, R., Sarabu, S., Bandari, S., Repka, M. A. "Effect of formulation and process variables on lipid based sustained release tablets via continuous twin screw granulation: A comparative study", European Journal of Pharmaceutical Sciences, 121, pp. 126-138, 2018.

https://doi.org/10.1016/j.ejps.2018.05.007

[17] Arndt, O.-R., Baggio, R., Adam, A. K., Harting, J., Franceschinis, E., Kleinebudde, P. "Impact of Different Dry and Wet Granulation Techniques on Granule and Tablet Properties: A Comparative Study", Journal of Pharmaceutical Sciences, 107(12), pp. 3143-3152, 2018.

https://doi.org/10.1016/j.xphs.2018.09.006

[18] Keleb, E. I., Vermeire, A., Vervaet, C., Remon, J. P. "Continuous twin screw extrusion for the wet granulation of lactose", International Journal of Pharmaceutics, 239(1-2), pp. 69-80, 2002. https://doi.org/10.1016/S0378-5173(02)00052-2

[19] Van Melkebeke, B., Vervaet, C., Remon, J. P. "Validation of a continuous granulation process using a twin-screw extruder", International Journal of Pharmaceutics, 356(1), pp. 224-230, 2008. https://doi.org/10.1016/j.ijpharm.2008.01.012

[20] Vercruysse, J., Córdoba Díaz, D., Peeters, E., Fonteyne, M., Delaet, U., Van Assche, I., De Beer, T., Remon, J. P., Vervaet, C. "Continuous twin screw granulation: Influence of process variables on granule and tablet quality", European Journal of Pharmaceutics and Biopharmaceutics, 82(1), pp. 205-211, 2012. https://doi.org/10.1016/j.ejpb.2012.05.010

[21] Djuric, D., Kleinebudde, P. "Impact of screw elements on continuous granulation with a twin-screw extruder", Journal of Pharmaceutical Sciences, 97(11), pp. 4934-4942, 2008.

https://doi.org/10.1002/jps.21339
[22] Dhenge, R. M., Fyles, R. S., Cartwright, J. J., Doughty, D. G., Hounslow, M. J., Salman, A. D. "Twin screw wet granulation: Granule properties", Chemical Engineering Journal, 164(2-3), pp. 322-329, 2010.

https://doi.org/10.1016/j.cej.2010.05.023

[23] Lute, S. V., Dhenge, R. M., Salman, A. D. "Twin Screw Granulation: An Investigation of the Effect of Barrel Fill Level", Pharmaceutics, 10(2), Article number: 67, 2018.

https://doi.org/10.3390/pharmaceutics10020067

[24] El Hagrasy, A. S., Hennenkamp, J. R., Burke, M. D., Cartwright, J. J., Litster, J. D. "Twin screw wet granulation: Influence of formulation parameters on granule properties and growth behavior", Powder Technology, 238, pp. 108-115, 2013. https://doi.org/10.1016/j.powtec.2012.04.035

[25] Dhenge, R. M., Cartwright, J. J., Hounslow, M. J., Salman, A. D. "Twin screw wet granulation: Effects of properties of granulation liquid", Powder Technology, 229, pp. 126-136, 2012. https://doi.org/10.1016/j.powtec.2012.06.019

[26] Yu, S., Reynolds, G. K., Huang, Z., de Matas, M., Salman, A. D. "Granulation of increasingly hydrophobic formulations using a twin screw granulator", International Journal of Pharmaceutics, 475(1-2), pp. 82-96, 2014. https://doi.org/10.1016/j.ijpharm.2014.08.015

[27] Dhenge, R. M., Cartwright, J. J., Hounslow, M. J., Salman, A. D. "Twin screw granulation: Steps in granule growth", International Journal of Pharmaceutics, 438(1-2), pp. 20-32, 2012. https://doi.org/10.1016/j.ijpharm.2012.08.049

[28] El Hagrasy, A. S., Litster, J. D. "Granulation rate processes in the kneading elements of a twin screw granulator", AIChE Journal, 59(11), pp. 4100-4115, 2013. https://doi.org/10.1002/aic.14180

[29] Li, J., Pradhan, S. U., Wassgren, C. R. "Granule transformation in a twin screw granulator: Effects of conveying, kneading, and distributive mixing elements", Powder Technology, 346, pp. 363-372, 2019. https://doi.org/10.1016/j.powtec.2018.11.099

[30] Pradhan, S. U., Zhang, Y., Li, J., Litster, J. D., Wassgren, C. R. "Tailored granule properties using 3D printed screw geometries in twin screw granulation", Powder Technology, 341, pp. 75-84, 2019. https://doi.org/10.1016/j.powtec.2017.12.068

[31] Sayin, R., El Hagrasy, A. S., Litster, J. D. "Distributive mixing elements: Towards improved granule attributes from a twin screw granulation process", Chemical Engineering Science, 125, pp. 165-175, 2015. https://doi.org/10.1016/j.ces.2014.06.040

[32] Vercruysse, J., Toiviainen, M., Fonteyne, M., Helkimo, N., Ketolainen, J., Juuti, M., Delaet, U., Van Assche, I., Remon, J. P., Vervaet, C., De Beer, T. "Visualization and understanding of the granulation liquid mixing and distribution during continuous twin screw granulation using NIR chemical imaging", European Journal of Pharmaceutics and Biopharmaceutics, 86(3), pp. 383-392, 2014. https://doi.org/10.1016/j.ejpb.2013.10.012 
[33] Thompson, M. R., Sun, J. "Wet Granulation in a TwinScrew Extruder: Implications of Screw Design", Journal of Pharmaceutical Sciences, 99(4), pp. 2090-2103, 2010.

https://doi.org/10.1002/jps.21973

[34] Meier, R., Thommes, M., Rasenack, N., Moll, K.-P., Krumme, M., Kleinebudde, P. "Granule size distributions after twin-screw granulation - Do not forget the feeding systems", European Journal of Pharmaceutics and Biopharmaceutics, 106, pp. 59-69, 2016. https://doi.org/10.1016/j.ejpb.2016.05.011

[35] Cartwright, J. J., Robertson, J., D'Haene, D., Burke, M. D., Hennenkamp, J. R. "Twin screw wet granulation: Loss in weight feeding of a poorly flowing active pharmaceutical ingredient", Powder Technology, 238, pp. 116-121, 2013. https://doi.org/10.1016/j.powtec.2012.04.034

[36] Kayrak-Talay, D., Litster, J. D. "A priori performance prediction in pharmaceutical wet granulation: Testing the applicability of the nucleation regime map to a formulation with a broad size distribution and dry binder addition", International Journal of Pharmaceutics, 418(2), pp. 254-264, 2011. https://doi.org/10.1016/j.ijpharm.2011.04.019

[37] Muehlenfeld, C., Thommes, M. "Miniaturization in Pharmaceutical Extrusion Technology: Feeding as a Challenge of Downscaling", AAPS PharmSciTech, 13(1), pp. 94-100, 2012. https://doi.org/10.1208/s12249-011-9726-7

[38] European Medicines Agency (EMA) "Guideline on process validation for finished products - information and data to be provided in regulatory submissions", [pdf] EMA, Amsterdam, The Netherlands, 2016. Available at: https:/www.ema.europa. eu/en/documents/scientific-guideline/guideline-process-validation-finished-products-information-data-be-provided-regulatory-submissions_en.pdf [Accessed: 06 July 2018]

[39] Almaya, A. "Development of Low-Dose Solid Oral Formulations Using Wet Granulation", In: Zheng, J. (ed.) Formulation and Analytical Development for Low-Dose Oral Drug Products, John Wiley \& Sons, Inc., Hoboken, NJ, USA, 2009, pp. 89-115. https://doi.org/10.1002/9780470386361.ch5

[40] US Pharmacopeia " $\langle 616\rangle$ Bulk Density and Tapped Density of Powders", [pdf] The United States Pharmacopeial Convention, North Bethesda, MD, USA, 2015. Available at: https:/www.usp. org/sites/default/files/usp/document/harmonization/gen-chapter/ bulk_density.pdf [Accessed: 12 December 2018]

[41] US Pharmacopeia " $\langle 1216\rangle$ Tablet Friability", [pdf] The United States Pharmacopeial Convention, North Bethesda, MD, USA, 2006. Available at: https://www.usp.org/sites/default/files/usp/document/harmonization/gen-chapter/g06_pf_ira_32_2_2006.pdf [Accessed: 07 August 2017]
[42] US Pharmacopeia "〈1174 $\rangle$ Powder Flow", [pdf] The United States Pharmacopeial Convention, North Bethesda, MD, USA, 2002. Available at: https://www.usp.org/sites/default/files/usp/ document/harmonization/gen-chapter/g05_pf_30_6_2004.pdf [Accessed: 05 January 2019]

[43] Sun, Z., Ya, N., Adams, R. C., Fang, F. S. "Particle Size Specifications for Solid Oral Dosage Forms: A Regulatory Perspective", American Pharmaceutical Review, [online] 1 May 2010. Available at: https://www.americanpharmaceuticalreview. com/Featured-Articles/36779-Particle-Size-Specificationsfor-Solid-Oral-Dosage-Forms-A-Regulatory-Perspective/ [Accessed: 06 January 2019]

[44] Shekunov, B. Y., Chattopadhyay, P., Tong, H. H. Y., Chow, A. H. L. "Particle Size Analysis in Pharmaceutics: Principles, Methods and Applications", Pharmaceutical Research, 24(2), pp. 203-227, 2007. https://doi.org/10.1007/s11095-006-9146-7

[45] European Medicines Agency "ICH Topic Q4B Annex 5 Disintegration Test General Chapter", [pdf] EMEA, Amsterdam, Netherlands, 2008. Available at: http://www.ema.europa.eu/ docs/en_GB/document_library/Scientific_guideline/2009/09/ WC500003292.pdf [Accessed: 02 September 2017]

[46] US Pharmacopeia " $\langle 905\rangle$ Uniformity of Dosage Units", [pdf] The United States Pharmacopeial Convention, North Bethesda, MD, USA, 2012. Available at: http://www.drugfuture.com/Pharmacopoeia/usp35/PDF/0420-0423\%20 [905]\%20UNIFORMITY\%20OF\%20DOSAGE\%20UNITS.pdf [Accessed: 08 February 2017]

[47] Moore, C. M. V. "Quality by Design - FDA Lessons Learned and Challenges for International Harmonization", [pdf] presented at International Conference on Drug Development, Austin, TX, USA, Feb., 28, 2012. Available at: https://www.fda.gov/downloads/ aboutfda/centersoffices/officeofmedicalproductsandtobacco/cder/ ucm341204.pdf [Accessed: 05 March 2017]

[48] Engisch, W., Muzzio, F. "Using Residence Time Distributions (RTDs) to Address the Traceability of Raw Materials in Continuous Pharmaceutical Manufacturing", Journal of Pharmaceutical Innovation, 11(1), pp. 64-81, 2016. https://doi.org/10.1007/s12247-015-9238-1 